\title{
(C) OPEN ACCESS \\ Effective physician leaders: an appreciative inquiry into their qualities, capabilities and learning approaches
}

\author{
Mairi Savage, ${ }^{1}$ Marie Höjriis Storkholm, ${ }^{1,2}$ Pamela Mazzocato, ${ }^{1}$ Carl Savage ${ }^{1}$
}

- Additional material is published online only. To view please visit the journal online (http://dx.doi.org/10.1136/ leader-2017-000050)

1Department of Learning, Informatics, Management and Ethics, Karolinska Institutet, Stockholm, Sweden ${ }^{2}$ Department of Obstetrics and Gynaecology, Aarhus University Hospital, Aarhus, Denmark

\section{Correspondence to Dr Carl Savage, Medical Management Centre, Department of Learning, Informatics, Management and Ethics, Karolinska Institutet, Stockholm 171 77, Sweden; carl.savage@ki.se}

Portions of the preliminary analyses were presented at the Swedish Healthcare Leadership Academy (Sjukvårdens Ledarskapsakademi), 2 December 2015, Stockholm, Sweden, and in leadership courses for medical students at the Karolinska Institutet, Stockholm, Sweden, taught by the authors during 2015 and 2016.

Received 25 September 2017 Revised 30 May 2018 Accepted 21 August 2018
Check for updates

(C) Author(s) (or their employer(s)) 2018. Re-use permitted under CC BY-NC. No commercial re-use. See rights and permissions. Published by BMJ.

To cite: Savage M, Storkholm MH, Mazzocato P, et al. BMJ Leader

2018:2:95-102.

\section{ABSTRACT}

Purpose The aim of this study was to explore the qualities and capabilities effective physician leaders attribute to their success in leading change and how they developed these.

Method The authors interviewed 20 emerging and senior leaders using a semistructured interview guide informed by appreciative inquiry. Data were subjected to an inductive qualitative content analysis to identify themes related to qualities, capabilities and learning approaches.

Results The qualities identified were clarity of purpose to improve care, endurance, a positive outlook and authenticity. They were considered innate or developed during participants' upbringing. Capabilities were to ground management in medicine, engage others, catalyse systems by acting on interdependencies and employ a scientific approach to understand problems and measure progress. Capabilities were developed through cross-pollination from a diversity of work experiences, reflection, when education was integrated with practice and when their organisational environment nurtured ambition and learning.

Conclusions This study reframes current leadership thinking by empirically identifying qualities, capabilities, and learning approaches that can contribute to effective physician leadership. Instead of merely adapting leadership development programmes from other domains, this study suggests there are capabilities unique to effective physician leadership: ground management in medicine and employ a scientific approach to problem identification and solution development. The authors outline practical implications for individuals and organisations to support leader development as a cohesive organisational strategy for learning and change.

\section{INTRODUCTION}

Physician leadership and management practices impact clinical and organisational outcomes, for example, effectiveness, efficiency, productivity, quality and work environment. ${ }^{1-3}$ They are essential to the development of new approaches to care delivery, organisational structures and governance, and often seen as a requisite for successful change efforts. $^{4}$ Consequently, physician competency models recognise leadership as a core component..$^{5-7}$

Despite these competency models and numerous leadership development efforts in healthcare, there is little evidence that either contribute to leader effectiveness. ${ }^{189}$ The existing evidence on effective leader and leadership development in and outside of healthcare is not being applied. ${ }^{3} 10$ The frequent use of brief programmes that focus on conceptual knowledge and individual skills training fail to address personal development and collaborative capacity-both cornerstones for effective leadership. ${ }^{8}$ The design and delivery commonly employ ineffective teaching approaches, lack relevant theoretical underpinnings and have limited adaptation to the healthcare context. ${ }^{19}$

In a complex context rife with adaptive challenges, physician leaders need more than a 'checklist' of competencies. ${ }^{11}$ While competencies are the application of knowledge, skills and attitudes to known problems with proven solutions, capabilities involve learning how to use and adapt these competencies in unfamiliar environments to address unfamiliar challenges. ${ }^{12}$ Given this difference, we need to understand how effective physician leaders have learnt to adapt their competencies to guide their organisations towards better performance. ${ }^{8}$ This identification of capabilities requires linking competencies to the effectuation of change.

Leader effectiveness and capability development are influenced by one's qualities (eg, open-mindedness, responsibility, courage). ${ }^{13}{ }^{14}$ In contrast to general leadership research, physician leaders' qualities have received little attention. Previous studies also have a methodological limitation: they identified qualities and/or competencies physicians perceived to be important, not those anchored in actual successful leadership experiences. ${ }^{15}$

Given the above, the aim of this study is to empirically explore the qualities and capabilities effective physician leaders attribute to their success in leading change, and how they think they developed these. We defined leadership as working towards continual organisational development, independent of formal authority or roles, that is, change (and its management) lies at the core of leadership. ${ }^{16} 17$

\section{METHOD}

\section{Study design}

We chose a qualitative interview study design to explore participants' experience in depth and address the lack of qualitative studies on effective teaching and learning approaches. ${ }^{9}$ The design was informed by appreciative inquiry (AI), a systematic approach to identify and analyse successful experiences and practices. ${ }^{18}$ AI suggests that by analysing successes instead of problems (the focus of traditional research), one is better able to identify and understand what actually works. It originated as a research methodology in studies conducted at the 
Cleveland Clinic and has been applied in healthcare (eg, hospital and primary care settings, nursing and obstetrics). ${ }^{19} 20$

\section{Study setting and participants}

This study was conducted in Sweden, which addresses the call for leadership research outside of North America. ${ }^{8}{ }^{9}$ Swedish healthcare is at the forefront of developing new models for care delivery, structure and governance, through quality improvement, lean, value-based healthcare and other initiatives. ${ }^{21} 22$

Our purposive sample included aspiring and senior physician leaders instrumental in these developments and with established records of accomplishment. ${ }^{23}$ An initial group of senior leaders was identified in consultation with professors at the Medical Management Centre, Karolinska Institutet, who possess a thorough understanding of the Swedish healthcare system based on decades of research. An initial group of emerging physician leaders was identified from the MedUniverse national physician network nomination list for their annual 'Future Physician Leader' prize. Nominees were physicians 45 years of age or younger who had demonstrated that they were 'visionary, role models, innovative, influential, and a positive force for leadership in Swedish healthcare. ${ }^{24}$ Thereafter, both groups were expanded and verified through cross-referencing and snowballing, where each respondent was asked to recommend other outstanding physician leaders.

\section{Data collection}

Data were collected through semistructured interviews. The interview guide consisted of three sections informed by AI (online supplementary appendix 1): (1) reflect on successful aspects of one's work and competence; (2) understand how past experiences enabled the development of qualities and capabilities relevant for leading change; and (3) ideas and suggestions to develop similar qualities and capabilities in future physician leaders. Qualities and capabilities were elicited in three ways: through direct questions; reflections about how others view the respondent's leadership; and a personal experience of leading what they defined as a successful change. The guide was pilottested thrice with individuals who shared the same profile as the participants. As the questions remained unchanged after the first pilot test, we included the two subsequent pilot tests.

Interviews were conducted together by the first and the last authors, both with considerable experience in qualitative research. Interviews lasted 60-80 $\mathrm{min}$, were digitally recorded and held at a convenient location for the participant, free from interruption. Three were conducted over the phone. Interviews were conducted in English with the option to answer in their native tongue (Swedish). Two chose to do so. Interviews were continued past the point of saturation for each group. ${ }^{25}$ Informed consent was received prior to the interview. Data were handled confidentially; all efforts were made to preserve anonymity.

\section{Data analysis}

Interviews were transcribed verbatim. Transcripts were read repeatedly to develop familiarity. Inductive content analysis $^{26}$ was performed using NVivo qualitative data analysis software; QSR International, V.10, 2012. Meaning units relevant to the research question were identified and coded by the first author. The analysis for the senior and emerging leaders was separated after observing different patterns in the codes. Codes were independently categorised by the first and the last authors and differences resolved through consensus. Each category was reviewed to develop subcategories and themes

\begin{tabular}{|c|c|c|}
\hline Characteristics & $\begin{array}{l}\text { Senior leaders } \\
(n=10)\end{array}$ & $\begin{array}{l}\text { Emerging leaders } \\
(n=10)\end{array}$ \\
\hline \multicolumn{3}{|l|}{ Sex } \\
\hline Male & 8 & 5 \\
\hline Female & 2 & 5 \\
\hline \multicolumn{3}{|l|}{ Degree } \\
\hline MD & 0 & 4 \\
\hline $\mathrm{MD} / \mathrm{PhD}$ & 7 & 3 \\
\hline MD/MBA* & 1 & 2 \\
\hline $\mathrm{MD} / \mathrm{PhD} / \mathrm{MBA}$ & 2 & 1 \\
\hline \multicolumn{3}{|l|}{ Work setting at the time of the interview } \\
\hline Management consulting & 3 & 2 \\
\hline Pharmaceutical company & 1 & 0 \\
\hline Private healthcare provider & 2 & 2 \\
\hline Academic medical centre & 4 & 6 \\
\hline Clinically active & 2 & 7 \\
\hline International management experience & 6 & 2 \\
\hline
\end{tabular}

${ }^{*}$ MBA: Master of Business Administration or other formal degree education equivalent in business or economics.

where applicable. To strengthen credibility, categorisation was repeated independently and corroborated by two other groups of six researchers each, and the transcripts were reread to ensure the themes accurately reflected what was said. Trustworthiness was strengthened through discussions with key informants and presentations. Given the growing interest among physicians for MBA programmes, ${ }^{27}$ we conducted an additional analysis to look at the potential impact of MBA training on leadership perspectives.

\section{RESULTS}

Study participants were 20 senior and emerging leaders (table 1). The emerging leader group was gender balanced; senior leaders consisted of more men than women. Specialties included internal medicine, family medicine, paediatrics, obstetrics/gynaecology, anaesthesiology, emergency medicine, psychiatry, cardiology and surgery. Sixteen had academic degrees in addition to their medical degree. All had worked in academic medical centres and the public sector.

We identified four themes among the qualities, four among the capabilities and five related to learning approaches. For illustrative quotations, consult tables 2-4.

\section{Qualities}

Participants attributed qualities such as clarity of purpose to improve care, endurance, positive outlook and authenticity to their success in leading positive change (table 2). They were driven by a purpose to improve healthcare and have a positive impact. For senior leaders, the impetus was dissatisfaction with the status quo. Emerging leaders acted on their ambition to implement new ideas.

For senior leaders, endurance meant to hold people accountable and always remind them of the larger purpose. Emerging leaders often faced resistance and thus needed endurance to keep 'standing tall' even if their proactive behaviour was not appreciated due to their junior status.

Both groups had a positive outlook. They were forward looking and focused on opportunities instead of problems. Emerging leaders emphasised the importance of positive reinforcement and feedback. Both described additional qualities 


\begin{tabular}{|c|c|c|}
\hline Themes & Senior leaders & Emerging leaders \\
\hline \multicolumn{3}{|l|}{ I. Clarity of purpose: improve care. } \\
\hline $\begin{array}{l}\text { I show such a passion for the patient. This is patient first, not just } \\
\text { words. I can always connect all my actions to why this is good for the } \\
\text { patient. (PS18)* }\end{array}$ & $\begin{array}{l}\text { Trigger to take a leadership role arises from a } \\
\text { perceived dissonance between the purpose of } \\
\text { healthcare and the status quo. }\end{array}$ & $\begin{array}{l}\text { Trigger to take a leadership role arises from their } \\
\text { ambition to implement new ideas to improve care. }\end{array}$ \\
\hline \multicolumn{3}{|l|}{ II. Endurance. } \\
\hline $\begin{array}{l}\text { You need to be willing to stick to it [a good goal], and keep going } \\
\text { back to it, even when it's not easy, even when it's tough - you just } \\
\text { keep going. And, in the end, you'll get there. (PS10) }\end{array}$ & $\begin{array}{l}\text { Follow-up, keep people accountable, remind them } \\
\text { about goals and purpose, take initiative even } \\
\text { in tough situations, remain true to one's own } \\
\text { principles and ethics. }\end{array}$ & $\begin{array}{l}\text { Stand tall, persist despite resistance, maintain drive } \\
\text { and ambition. }\end{array}$ \\
\hline \multicolumn{3}{|l|}{ III. Positive outlook. } \\
\hline $\begin{array}{l}\text { People need energy and something I've learned is that everyone } \\
\text { wants to be seen. That holds true for anyone at any level. And people } \\
\text { feel more seen if [...] you give them opportunities to actually present } \\
\text { and discuss and you do that by being open, so I think enthusiasm and } \\
\text { openness go hand in hand. (PE05)* }\end{array}$ & $\begin{array}{l}\text { Look forward, see possibilities, demonstrate } \\
\text { enthusiasm and energy. }\end{array}$ & $\begin{array}{l}\text { Focus on opportunities instead of problems, receive } \\
\text { positive reinforcement and feedback, demonstrate } \\
\text { enthusiasm and energy. }\end{array}$ \\
\hline \multicolumn{3}{|l|}{ IV. Authenticity. } \\
\hline $\begin{array}{l}\text { I had to be sincere, honest, and really try to get the discussions down } \\
\text { to facts and also try to, as often as I could, demonstrate how we had } \\
\text { come to the decision. (PS14) }\end{array}$ & Humility, openness, listen, be trustworthy, passion. & $\begin{array}{l}\text { Humility, openness, ambitious, curious, } \\
\text { professional, demonstrate commitment. }\end{array}$ \\
\hline
\end{tabular}

*PS: senior leaders. PE: emerging leaders.

related to authenticity, such as humility, openness, trustworthiness, professionalism and curiosity.

\section{Capabilities}

The capabilities were to ground management in medicine, engage others, catalyse systems by acting on interdependencies and employ a scientific approach to understand problems and measure progress (table 3 ).

\section{Ground management in medicine}

Participants integrated their knowledge of medicine with that of economics, quality improvement and organisational development to help others see the rationale for change. Their in-depth medical knowledge and understanding of care processes granted them credibility among staff, and it helped them understand and address the medical consequences of change initiatives.

\section{Engage others: 'Working with the system' versus 'working the} system'

When engaging others, participants empathised with staff, maintained motivation and developed resonant relationships. However, there was a distinction in how they related to their context. Senior leaders 'worked with the system.' They mediated conflicting interests by focusing on a shared purpose and brought together strategic allies. They engaged and empowered staff by creating space and challenging them to take the lead in problem identification and solution development by being present and visible in the organisation. They did not rush to solve problems for others, but through delegation and sharing their decision-making powers, got others to identify problems and develop solutions themselves. Senior leaders listened first to truly understand and empathise with what matters to people.

Emerging leaders, on the other hand, 'worked the system.' Without a formal position of authority, they built support by negotiating terms and teamed with people whose competencies compensated for their own shortcomings. They engaged others in change initiatives by asking questions that tested their own hypotheses about the situation. They too listened to people, but it was in order to understand how to tailor their communication and demonstrate good social skills.
Catalyse systems by acting on interdependencies

Participants recognised patterns and led by example; using themselves as learning tools. They connected ideas (senior) and acted on the interdependencies in the system through goal setting and providing structure (emerging).

They saw themselves as part of everything that was going on in the system. Senior leaders reflected on the importance of improving self-awareness through testing ideas on themselves. Emerging leaders 'walked the talk' as a strategy to illustrate the validity of their ideas.

Employ a scientific approach to understand problems and measure progress

Participants used a scientific approach to analyse problems, develop hypotheses and measure progress. Senior leaders described this as being curious, asking questions and listening carefully to be able to understand problems before jumping into solutions. Emerging leaders talked about maintaining a healthy scepticism and the importance of critical thinking, in particular to check and analyse the data used to inform decisions.

\section{Learning approaches}

The most influential learning approaches were cross-pollination from a diversity of work experiences, reflection, the rare occasions when education was integrated with practice, being part of an environment that nurtured ambition and learning and 'luck of the draw' (table 4).

Both groups valued 'learning by doing'. Emerging leaders described taking responsibility for increasingly larger projects over time. Both groups credited experiences from medical practice as important in developing emotional intelligence, skills in communication and quick decision-making. While medical practice was a central work experience for both groups, participants also found it important to seek out roles in other contexts and leave their 'medical comfort zone'. This was primarily tied to rethinking how medicine works based on a diversity of work experiences in management and health economics consulting, pharma, medical entrepreneurship or at the WHO. Teaching and mentoring-helping others develop new behaviours-as well as being a mentee, were also seen as a practice of leadership. 
Table 3 Capabilities of senior and emerging leaders

\begin{tabular}{|c|c|c|}
\hline Themes and categories & Senior leaders & Emerging leaders \\
\hline \multicolumn{3}{|l|}{ I. Ground management in medicine. } \\
\hline $\begin{array}{l}\text { It is the [patient] flows and the consequences. That is what one } \\
\text { must be able to speak about. If you can't do that, well, that is why I } \\
\text { also think that it is important to have doctors as the top managers. } \\
\text { (PS17)* }\end{array}$ & $\begin{array}{l}\text { Combine in-depth medical knowledge with } \\
\text { organisational development, economics and } \\
\text { quality improvement to understand the medical } \\
\text { consequences of management decisions. }\end{array}$ & $\begin{array}{l}\text { Continually expand knowledge in medicine and } \\
\text { management. }\end{array}$ \\
\hline II. Engage others. & 'Work with the system.' & 'Work the system.' \\
\hline \multicolumn{3}{|l|}{ Relate to stakeholders in the system. } \\
\hline $\begin{array}{l}\text { If you want something to change you have to tell everyone: the } \\
\text { government, the Department of Health, the politicians, so that } \\
\text { they know that what I want is this. Because if you want to change } \\
\text { something you will always have to sell something as well. (PE12)* }\end{array}$ & $\begin{array}{l}\text { Mediate conflicting interests by focusing on shared } \\
\text { purpose. }\end{array}$ & Negotiate to build support among decision makers. \\
\hline
\end{tabular}

Bring together the right people.

I'm strategic in cuddling up with people with more knowledge Find strategic allies.

Compensate for own limitations through other's competencies.

in areas I don't have [...] I create a team around myself that can

influence others so that if needed, I can say, "I don't know this very

well, but this person does". This team building is a strength. (PE19)

Engage staff in change initiatives.

They joined me and we planned and followed-up and so forth, so we really shared it all. (PS16)

Listen to engage.

I suppose I think rather quickly and I've learned over time not to speak first, but to wait for the others. (PS11)

Develop resonant relationships.

At the end of the day, it's actually about impacting the organization Seek to understand what matters to peoplein a way that really matters. The only way you can reach that is, of course, by working [with] the organization's people [...] the actual empathise, motivate and inspire. people who are going to be the agents of change. (PE05)

III. Catalyse systems by acting on interdependencies.

Recognise patterns.

I also think that I have a tactical or strategic sense for possibilities Connect ideas, help others to see the big picture. so that I can see things within the system that are not linked today, but I can actually see that if I can connect this person to that person, whether I'm going to be a part of that or not, it might

Be present and engage staff in order to identify problems, their root cause, and develop solutions.

Listen first. Tell stories, inspire, walk the floors to keep people focused on goals. actually lead to something that is interesting. (PE04)

Lead by example by using oneself as a learning tool.

The only [learning] tool I have is myself, really, so, in that way I sort Improve self-awareness by using oneself as a of learn and then see reactions from people. (PS14)

learning tool. Test changes on oneself.

IV. Employ a scientific approach to understand problems and measure progress.

First you take a step back and you see the whole process and then you have to start measuring and see what data you have and if it supports you or not. [...] it is not enough to just have a lot of figures and measurements [...] you have to draw conclusions from Be curious, ask questions and collect and analyse data to understand problems before jumping into solutions. Measure progress. social skills.

Ask questions and facilitate discussions to test hypotheses.

Listen in order to tailor communication approach.

Be curious and interested in others, develop good

See interdependencies in order to develop a strategic mindset to spot opportunities, set goals, develop action plans, provide structure and grow networks.

'Walk-the-talk' as a strategy to convince others.

Maintain a healthy scepticism and think critically. Systematically collect and use data to analyse problems and measure progress. it as well. (PE07)

${ }^{*} \mathrm{PS}$ : senior leaders. PE: emerging leaders.

Reflection was facilitated through feedback and evaluation, observations and the use of theories. Emerging leaders appreciated the regular feedback and evaluation systems they experienced in management consulting companies and were consequently more aware of their own strengths and weaknesses compared with senior leaders. Observations allowed both groups to recognise good and bad leadership practices. Theory allowed them to make sense of their experiences (senior), and if successfully applied, generated enthusiasm for their leadership practice (emerging). Formal education was deemed useful only if integrated with practice. An organisational environment that nurtured ambition and learning helped create opportunities to practise and improve one's leadership capabilities.

Qualities such as openness, honesty, commitment, competence, passion, enthusiasm, humility, curiosity, ambition and persistence were attributed to 'luck of the draw' in terms of both, 'just the way I am' (nature) or to one's upbringing (nurture). This was irrespective of growing up in a supportive family or one full of hardships.

Of the six participants with an MBA or equivalent degree, none described being open minded, curious or humble. As for those with consulting backgrounds, there was a clear emphasis on project management as well as on strategic thinking in terms of structure, prioritisation, process and analysis. In terms of their learning approach, they were more externally orientated as opposed to engaging regularly in self-reflection. Two of the six described that they found their MBA education useful, either for learning about communication or making sense of past management experiences. They valued working on real-life projects or their own cases.

\section{DISCUSSION}

The senior and emerging leaders in our study attributed their success in leading positive change to their qualities of a clarity 
Table 4 Effective learning approaches used by senior and emerging leaders

\begin{tabular}{|c|c|c|}
\hline Themes and categories & Senior leader & Emerging leader \\
\hline \multicolumn{3}{|l|}{ I. Cross-pollination from a diversity of work experiences. } \\
\hline \multicolumn{3}{|l|}{ Learning by doing. } \\
\hline $\begin{array}{l}\text { When you actually get to try something and it works it's } \\
\text { fantastic. When you try something and it doesn't work } \\
\text { it's not fantastic, but you learn more (laughs) probably, } \\
\text { from your mistakes than you learn from your successes. } \\
(\text { PS11)* }\end{array}$ & Learn from experiences. & Take responsibility for increasingly larger projects. \\
\hline
\end{tabular}

Learn from medical practice.

You work in teams, you work in different situations where Communication skills, experience from different levels of the Fast decision-making, emotional intelligence, openyou have to learn how to see people and tell what they're organisation allowed them to adapt argumentation approach mindedness developed through the experience of clinical feeling. And you are used to taking in a lot of information and manage expectations. rotations.

in a short time and you need to make a decision in a

short time. (PE08)*

Leave your medical comfort zone.

If you are a young doctor and you want to go into Formulate questions, client focus, adaptability, relationship [leadership], you need to leave your comfort zone. (PS15) building, adapt management ideas into medicine.

Challenge one's professional status, apply similar strategies across projects, problem solving, structure, work with data, presentation skills.

Be a teacher and/or mentor.

I see a lot of overlap between facilitation and improvement and pedagogical activities where you also facilitate learning. In one sense, it's learning what you

Teaching and mentoring was an integral part of senior roles and seen as acts of leadership to help others develop new

Facilitating learning for others was experienced as a trigger to behaviours. learn, particularly about group dynamics. eed to do to teach the subject and in another way it's learning about the situation or about a shared problem. (PE04)

II. Reflection.

Feedback and evaluation.

[...] during projects and between projects, on a yearly basis, structured evaluations and feedback, which are very good because we go over my good and bad traits and efforts and how to improve. (PE13)

Observation.

[...] being able to learn from negative mentoring has been very useful [laughs] [...] You see the consequences of different kinds of behaviours - the disruption and discomfort. (PS10)

Use theory to reflect on practice.

[An MBA] made me understand the systematics of what I intuitively felt before and I understood the frameworks and theories. (PS18)

III. Education integrated with practice.

I really learn much more when I can work as a manager and then go to courses at the same time and I can think about what I do in my role as a manager from different perspectives. (PE19)

IV. Organisational environment that nurtures ambition and learning.

I'm quite a confident person, both as a person and in my professional role [but] it's still really important to have people around you who believe in you. It's not enough to believe in yourself and I think that makes the difference. (PE21)

Coaching and mentoring by more senior people.

Negative examples of leadership.

Collected observations of people and groups.
Make systematic approaches to feedback and evaluation as well as senior colleagues a part of daily work.

Theory helps make sense of and frame one's experiences.

MBA programmes that gave space to work on one's own cases. A systems science course improved understanding of quality improvement and ability to see interdependencies.
Situations where theory was experienced as applicable to practice contributed to enthusiasm about work.

Formal education was a tool to establish credibility, become professional and develop networks, communication skills and personal leadership. It triggered further interest in management.

Both groups attributed learning to their organisational contexts, particularly being surrounded by people who had faith in their capabilities, were interested in their input, supportive and encouraged openness, courage, ambition, commitment, creativity and honesty.

uck of the draw.

Nature.

You can't educate these things. You can modify a good person to be better. It is basically in the personality and then, of course, your social background. (PS18)

Nurture.

It's definitely lots of genetics, but it's also my upbringing Upbringing encouraged openness, honesty, commitment, that's shaped me more than anything. (PE21) Upbringing encouraged openness, honesty,
competence, clarity, passion, persistence.

Born this way/genetics: openness, honesty, commitment

competence, clarity, passion, persistence
Born this way/genetics:

humility, openness, ambition, curious, enthusiastic, positive, ability to learn

During upbringing learnt to take responsibility, observe prioritise academic achievement, connect with people.

*PS: senior leaders. PE: emerging leaders.

of purpose to improve care, endurance, a positive outlook and authenticity, as well as their capability to ground management in medicine, engage others, catalyse systems by acting on interdependencies and employ a scientific approach to understand problems and measure progress. Qualities were seen as either innate or nurtured during their upbringing. Capabilities were developed through cross-pollination from a diversity of work experiences, (self-)reflection, those rare occasions when education provided insight into concurrent work challenges and when they were part of or created an organisational environment that encouraged learning and placed high expectations on them.

At first glance, the findings may seem similar to general leadership theories, which raises the question of the uniqueness of physician leadership. ${ }^{15}$ However, those theories have proven 
difficult to translate into healthcare. ${ }^{1}$ We suggest that there are nuanced and important differences which we explore below.

While previous studies have highlighted the necessity of clinical knowledge, ${ }^{32328}$ our participants articulated and took action based on the medical consequences of management decisions. This allowed both the emerging and senior leaders to achieve their organisation's (often economic) goals without compromising their integrity of purpose to improve care. This is in contrast to a previous study where such purpose-driven behaviour, described as organisational altruism, was observed only among established leaders. ${ }^{23}$ The integration of tasks in conflicting domains, such as economics and patient care, may have been further facilitated by their ability to authentically engage others. ${ }^{29}$ This in turn helps retain motivation and well-being among staff, ${ }^{30}$ even in the face of considerable downsizing requirements. ${ }^{31}$ Thus, leadership which facilitates medical engagement, that is, the strategic involvement of physician leaders in improving care, is worth further study. 3233

Integral and unique to the physicians' leadership was their scientific mindset. Similar to findings by Hopkins et al, ${ }^{28}$ participants looked for the most pertinent questions to pose and data that could help to answer these questions and measure progress. This went beyond the 'management by analysis' training of the $\mathrm{MBAs}^{34}$ and is rare even in quality improvement efforts $(15 \%))^{35}$ We could not find any study that linked educational level with healthcare leadership effectiveness and can therefore only speculate that since 13 of the 20 participants had doctoral degrees, the research skills they had developed may have influenced their leadership practice. Such an evidence-informed 'scientific' approach may resonate better with the professional ethos of healthcare staff who commonly understand change as a result of new research findings, ${ }^{31}$ and may exemplify the kind of evidence-based management needed in healthcare. ${ }^{36}$

\section{Focus on learning}

Leadership studies and competency models frequently stress the importance of goals and performance. Participants were indeed accomplished high achievers. However, from the data it emerged they were first and foremost avid learners-they treated each situation as an opportunity to learn about others, themselves and their context. Their qualities and capabilities combined to engender a continual focus on learning.

Participants differed from colleagues who, prone to overconfidence, avoid challenges that question their competence, that is, a 'fixed mind-set' that impedes learning. ${ }^{37}$ Instead, they demonstrated qualities that contributed to a habit to critically reflect, ${ }^{14}$ actively seek out challenging situations and expand their role and mandate, that is, they demonstrated a 'growth mind-set'. ${ }^{37}$ Their positive outlook can be linked to improved cognitive functioning, including an openness to ideas, emotions and people. ${ }^{38}$ Hopkins et al describe similar distinguishing leadership behaviours in terms of creating opportunities for learning and being open to new perspectives. ${ }^{28}$

Despite growing evidence for the role of teamwork to achieve better clinical outcomes, ${ }^{39} 40$ participants seldom described such teamwork in their leadership efforts. Instead, they consistently developed resonant relationships and collaborated with a broad range of stakeholders. ${ }^{23} 28$ The findings suggest that physician leaders may benefit from moving beyond popular team-training initiatives designed for stable membership and well-defined tasks. ${ }^{41}$ Participants' approaches could be characterised rather as 'teaming' or relational coordination, which involves creating meaningful multidisciplinary relationships 'on the fly' in a shifting mix of work-partners. ${ }^{41-43}$ The combination of such dynamics and participants' approach to relationships attests to their emotional and social intelligence-both increasingly acknowledged attributes for effective physician leaders. ${ }^{23} 284445$

As systems catalysts, participants demonstrated more than the basic understanding of how health systems function and systembased patient care described in physician competency models. ${ }^{5646}$ Not only could they see interdependencies, ${ }^{28}$ these leaders were aware of their own role in them. In contrast to several studies of physician leadership which see change as a result of the deliberate communication of leaders' own visions, ${ }^{323}$ our participants took action based on the full acknowledgement of their organisations' complexity, that is, visions were created in concert with others. $^{47}$

\section{Insights on learning from effective physician leaders}

A comparison of leadership development in healthcare ${ }^{89}$ with leadership development research ${ }^{10}$ reveals two insights empirically supported in this study: daily work as a platform for deliberate leadership practice and a symbiosis between organisational learning culture and effective leadership development.

\section{Transform learning from experience into deliberate practice}

Participants' descriptions of learning from a diversity of work experiences support the proposition that leadership development should be about 'helping people learn from their work rather than taking them away from their work to learn. ${ }^{, 17}$ However, learning from experience can be problematic. ${ }^{11}$ For technical problems, such as perfecting a surgical technique, repetition might be enough. But for more complex challenges, learning from experience is only effective when coupled with reflection and high-quality feedback. ${ }^{48}$

Feedback and evaluations were valued for improving self-awareness, which, in healthcare leadership programmes, is often missed. ${ }^{8}$ Systematic feedback, however, does not guarantee behaviour change-it was participants' focus on learning, which helped them benefit from these practices. ${ }^{10}$ Their reflective practice helped them transform implicit (performance-oriented) work experiences into explicit learning opportunities, ${ }^{14}$ that is, transform learning from experience into deliberate practice. ${ }^{48}$

A symbiosis between organisational learning culture and leadership development

Healthcare, with its noticeable status differences and promotion of individual accomplishments, seldom exhibits a learning culture supportive of leadership development. ${ }^{11} 2349$ Still, as participants engaged others, they fostered a coherent organisational learning environment based on reciprocal relationships centred around shared meaning that provides assessment, challenge and support at all levels. ${ }^{10}$ This is in line with effective leader and leadership development, ${ }^{10}$ and why current teaching methods (lectures, seminars and group work) focused on individual leaders are not enough. ${ }^{8}$

Our study has limitations. Despite the critique of AI's penchant for the positive, interviews also elicited challenges and negative experiences, but the emphasis was on what lessons have been learnt for future success. ${ }^{50}$ The first and last authors' considerable experience with applying $\mathrm{AI}$ in the contexts of primary care, psychiatry, medical and leadership education, public health and global NGO development may have enabled this. We acknowledge the imbalance among the sexes of the senior leaders; however, no gender differences were identified among emerging leaders, which may suggest that the same holds true for senior 
Table 5 Implications for physician leadership development

\begin{tabular}{ll}
\hline Individuals aspiring to leadership and management positions & Leadership development programmes \\
\hline Engage in self-reflection around the qualities necessary to develop a focus on learning. & $\begin{array}{l}\text { Support a growth mindset through establishing psychological safety and a learning } \\
\text { orientation. }\end{array}$ \\
$\begin{array}{l}\text { Ground management practices in medicine through clinical knowledge and clarity of } \\
\text { purpose. }\end{array}$ & $\begin{array}{l}\text { Facilitate clarity of purpose and help physician leaders develop the wisdom and tools to } \\
\text { engage others in healthcare improvement. }\end{array}$ \\
$\begin{array}{l}\text { Work with others by 'working the system' or 'working with the system' (dependent on } \\
\text { one's level of authority) through teaming. }\end{array}$ & $\begin{array}{l}\text { Help participants to practise addressing actual challenges in changing team } \\
\text { constellations. }\end{array}$ \\
$\begin{array}{l}\text { Become systems catalysts and use oneself as a learning tool. } \\
\text { Help participants develop a systems perspective through observations, identification of } \\
\text { interdependencies and analysis of situations through the lens of different parties and } \\
\text { provide training in how to engage others in multistakeholder change processes. }\end{array}$ \\
$\begin{array}{l}\text { Cultivate a scientific mindset that guides the analysis of problems and the } \\
\text { measurement of progress. }\end{array}$ & $\begin{array}{l}\text { Link a scientific mindset to organisational improvement efforts by requiring that projects } \\
\text { be anchored in evidence and use data to inform decisions and learning. }\end{array}$ \\
\hline
\end{tabular}

leaders. As with qualitative studies in general, transferability is determined by how the description of the context, characteristics of the participants and the findings resonate with readers. Further studies could be conducted in the context of a leadership development effort to explore the mechanisms that foster learning and change. ${ }^{8} \mathrm{~A}$ further analysis of the change strategies described by participants could contribute to a theory of physician leadership.

\section{Implications for practice}

Organisations could take a proactive and long-term approach to cultivate the qualities of clarity of purpose, endurance, positive outlook and authenticity that foster learning from experience. Recruiting and developing managers with these qualities may generate a virtuous cycle where staff become aware of and challenge their fixed mindsets. Further suggestions for individuals and organisations are summarised in table 5.

A first step would be to move from haphazard self-reflection to facilitate the deliberate practice of leadership in daily (clinical) work. This could help organisations integrate leader and leadership development at all levels in a cohesive organisational strategy and learning environment that challenges aspiring leaders to grow their best selves at work.

\section{CONCLUSIONS}

This study reframes current leadership thinking by empirically identifying the qualities, capabilities and learning approaches that can contribute to effective physician leadership. Our findings resonate with cutting-edge leadership research that builds on complexity science, but which thus far has failed to make segues into healthcare. Instead of merely adapting leadership development programmes from other domains, this study suggests there are capabilities unique to effective physician leadership: ground management in medicine and employ a scientific approach to problem identification and solution development. The need for more physician engagement in the management and leadership of healthcare may be better addressed if leadership development meaningfully resonates with clinical practice and professional ethos.

\section{Twitter@SavageCarl}

Acknowledgements The authors thank the Clinical Management research group at the Medical Management Centre, KI, for comments on previous drafts. They also thank Louise Parke, George Keel, Rafiq Muhammad, Anne Leppänen and Sofia Sveréus for their contribution to the analysis; Mats Brommels, Carl Johan Sundberg, Ulrika Schüldt Håård and the late Mikael Thollander for their input in the early phase of this study; and the interviewees for enthusiastically sharing their time and reflections.
Contributors MS and CS designed the study, recruited participants and collected the data. MS, MHS, PM and CS conducted the analyses. MS drafted the manuscript. MS and CS rewrote and revised the study with invaluable input from MHS and PM. All authors read, contributed to and approved the final manuscript. CS was the principal investigator and submitted the study.

Funding MS was financially supported by a grant from AFA Insurance (\#150162), with additional financial support for MS and CS from the Torsten Söderberg Foundation (\#ET4/12). PM was supported by a grant from the Strategic Research Area Health Care Science, Karolinska Institutet/Umeå University.

Competing interests None declared.

Patient consent Not required.

Ethics approval The study was approved by the Stockholm Regional Ethical Vetting Board (2015/197-31/5).

Provenance and peer review Not commissioned; externally peer reviewed.

Open access This is an open access article distributed in accordance with the Creative Commons Attribution Non Commercial (CC BY-NC 4.0) license, which permits others to distribute, remix, adapt, build upon this work non-commercially, and license their derivative works on different terms, provided the original work is properly cited, appropriate credit is given, any changes made indicated, and the use is non-commercial. See: http://creativecommons.org/licenses/by-nc/4.0/

\section{REFERENCES}

1 West M, Armit K, Loewenthal L. Leadership and leadership development in health care: the evidence base. The Kings Fund 2015:1-36.

2 Sarto F, Veronesi G. Clinical leadership and hospital performance: assessing the evidence base. BMC Health Serv Res. 2016;16(S2):85-97.

3 Gilmartin MJ, D'Aunno TA. 8 leadership research in healthcare. Acad Manag Ann 2007; 1:387-438

4 Ham C. Improving the performance of health services: the role of clinical leadership. Lancet 2003;361:1978-80.

5 Frank J, Snell L. CanMEDS 2015 physician competency framework. Ottawa: Royal College of Physicians and Surgeons of Canada, 2015.

6 Combes J, Arespacochaga E. Lifelong learning: physician competency development. Chicago: Royal College of Physicians and Surgeons of Canada, 2012.

7 Leadership Academy NHS. Healthcare leadership model : The nine dimensions of leadership behaviour. NHS Leadership Academy 2013:1-16.

8 Frich JC, Brewster AL, Cherlin EJ, et al. Leadership development programs for physicians: a systematic review. J Gen Intern Med 2015;30:656-74.

9 Straus SE, Soobiah C, Levinson W. The impact of leadership training programs on physicians in academic medical centers: a systematic review. Acad Med 2013:88:710-23.

10 Day DV, Fleenor JW, Atwater LE, et al. Advances in leader and leadership development: a review of 25years of research and theory. Leadersh Q 2014;25:63-82.

11 Carroll JS, Edmondson AC. Leading organisational learning in health care. Qual Saf Health Care 2002;11:51-6.

12 Fraser SW, Greenhalgh T. Coping with complexity: educating for capability. BMJ 2001;323:799-803.

13 Lord RG, Hall RJ. Identity, deep structure and the development of leadership skill. Leadersh Q 2005;16:591-615.

14 Densten IL, Gray JH. Leadership development and reflection: what is the connection? Int J Med Educ 2001;15:119-24.

15 Dinh JE, Lord RG, Gardner WL, et al. Leadership theory and research in the new millennium: current theoretical trends and changing perspectives. Leadersh $Q$ 2014;25:36-62. 
16 Marion R, Uhl-Bien M. Leadership in complex organizations. Leadersh Q 2001;12:389-418.

17 Day D V. Leadership development. a review In Context 2001;11:581-613.

18 Cooperrider DL, Whitney D, Stavros JM. Appreciative inquiry handbook: the first in a series of Al workbooks for leaders of change. San Francisco, CA: Lakeshore communications inc. and Berrett-Koehler Publishers, 2003.

19 Bushe GR, Burnes D, Hassard D. Appreciative inquiry : theory and critique. In: Boje D, Burnes B, Hassard J, eds. The Routledge Companion To Organisational Change. Oxford, UK: Routledge, 2011: 87-103.

20 Trajkovski S, Schmied V, Vickers M, et al. Using appreciative inquiry to transform health care. Contemp Nurse. 2013;45:95-100.

21 Mazzocato P, Thor J, Bäckman U, et al. Complexity complicates lean: lessons from seven emergency services. J Health Organ Manag 2014;28:266-88.

22 Shah A. Value-based health care, a global assessment. London, 2016

23 Taylor CA, Taylor JC, Stoller JK. Exploring leadership competencies in established and aspiring physician leaders: an interview-based study. J Gen Intern Med 2008:23:748-54.

24 Meduniverse, 2013. [Future leaders among physicians] Framtidens ledare i läkarkåren. Available from: www.meduniverse.se/framtidens-ledare/kriterier [accessed $17 \mathrm{Apr}$ 2015].

25 Robinson OC. Sampling in Interview-based qualitative research : a theoretical and practical guide a theoretical and practical Guide. Qualitative Research in Psychology 2014;11:25-41.

26 Graneheim UH, Lundman B. Qualitative content analysis in nursing research: concepts, procedures and measures to achieve trustworthiness. Nurse Educ Today 2004:24:105-12.

27 Patel MS, Arora V, Patel MS. The role of MD and MBA training in the professional development of a physician: a survey of 30 years of graduates from the whaWharton health care management Program. Acad Med 2014;89:1-5.

28 Hopkins MM, O'Neil DA, Stoller JK. Distinguishing competencies of effective physician leaders. Journal of Management Development 2015;34:566-84.

29 Wikström E, Dellve L. Contemporary leadership in healthcare organizations. J Health Organ Manag 2009;23:411-28.

30 Bergin E, Savage C. Surviving multiple obligations through stimulation, autonomy, and variation. J Health Organ Manag 2011;25:455-68.

31 Storkholm MH, Mazzocato P, Savage M, et al. Money's (not) on my mind: a qualitative study of how staff and managers understand health care's triple Aim. BMC Health Serv Res 2017;17:98

32 Baker GR, Denis J-L. Medical leadership in health care systems: from professional authority to organizational leadership. Public Money \& Management 2011;31:355-62.

33 Spurgeon P, Mazelan PM, Barwell F. Medical engagement: a crucial underpinning to organizational performance. Health Serv Manage Res 2011;24:114-20.
34 Mintzberg H. Managers, not MBAs : a hard look at the soft practice of managing and management development. 1st edn. San Francisco: Berrett-Koehler Publishers, 2004.

35 Taylor MJ, McNicholas C, Nicolay C, et al. Systematic review of the application of the plan-do-study-act method to improve quality in healthcare. BMJ Qual Saf 2014;23:290-8.

36 Walshe K, Rundall TG. Evidence-based management: from theory to practice in health care. Milbank Q 2001;79:429-57.

37 Ehrlinger J, Mitchum AL, Dweck CS. Understanding overconfidence: theories of intelligence, preferential attention, and distorted self-assessment. J Exp Soc Psychol 2016:63:94-100.

38 Boyatzis RE. Leadership development from a complexity perspective. Consulting Psychology Journal: Practice and Research 2008;60:298-313.

39 Wheeler D, Teamwork SJK. Teambuilding and leadership in respiratory and health c are. Canadian Journal of Respiratory Therapy 2011;47:6-11.

40 Neily J, Mills PD, Young-Xu Y, et al. Association between implementation of a medical team training program and surgical mortality. JAMA 2010;304:1693-700.

41 Nawaz H, Edmondson AC, Tzeng TH, et al. Teaming: an approach to the growing complexities in health care: AOA critical issues.J Bone Joint Surg Am 2014;96:e184-1-7

42 FairfieldGittell JH. Impact of relational coordination on quality of care, postoperative pain and functioning, and length of stay : a nine-hospital study of surgical patients. Medical Care 2018:38:807-19.

43 Edmondson AC. Teaming: how organizations learn, innovate, and compete in the knowledge economy. San Francisco, CA: John Wiley \& Sons, 2012.

44 Mintz LJ, Stoller JK. A systematic review of physician leadership and emotional intelligence. J Grad Med Educ 2014:6:21-31.

45 Nowacki AS, Barss C, Spencer SM. Emotional intelligence and physician leadership potential: a longitudinal study supporting a link. J Health Adm Educ 2016;33:23-41.

46 Calhoun JG, Dollett L, Sinioris ME, et al. Development of an interprofessional competency model for healthcare leadership. J Healthc Manag 2008;53:375-89.

47 Uhl-Bien M, Marion R, McKelvey B. Complexity leadership theory: shifting leadership from the industrial age totheexity Leadership Theory: Shifting leadership from the industrial age to the knowledge era. Leadersh Q 2007;18:298-318.

48 Day DV. The difficulties of learning from experience and the need for deliberate practice. Ind Organ Psychol 2010;3:41-4.

49 Blumenthal DM, Bernard K, Bohnen J, et al. Addressing the leadership gap in medicine: residents' need for systematic leadership development training. Acad Med 2012;87:513-22.

50 Sidebotham M, Fenwick J, Rath S, et al. Midwives' perceptions of their role within the context of maternity service reform: an appreciative inquiry. Women Birth 2015;28:112-20. 